\title{
Prospective Evaluation of Outcomes of Mechanical Devices in Women with Symptomatic Pelvic Organ Prolapse in Ogbomoso, South-Western Nigeria
}

\author{
Akintunde Olusegun Fehintola ${ }^{*}$, Olufemi Timothy Awotunde ${ }^{2}$, Olumuyiwa Ayotunde Ogunlaja ${ }^{2}$, \\ Lawrence Olujire Olujide ${ }^{3}$, Samuel Eniola Akinola ${ }^{2}$, Sunday Adekunle Oladeji², \\ Babatola Bakare4, Olurotimi Idowu Aaron'5 \\ ${ }^{1}$ Department of Obstetrics, Gynaecology, and Perinatology, Obafemi Awolowo University, Ile-Ife, Osun State, Nigeria \\ ${ }^{2}$ Department of Obstetrics and Gynaecology, Bowen University Teaching Hospital, Ogbomoso, Oyo State, Nigeria \\ ${ }^{3}$ Department of Obstetrics and Gynaecology, Royal Hampshire County Hospital, Winchester, UK \\ ${ }^{4}$ Department of Obstetrics \& Gynaecology, Unimed Teaching Hospital, Ondo, Ondo State, Nigeria \\ ${ }^{5}$ Department of Anaesthesia, Obafemi Awolowo University, Ile-Ife, Osun State, Nigeria \\ Email: *akintunds@yahoo.com
}

How to cite this paper: Fehintola, A.O., Awotunde, O.T., Ogunlaja, O.A., Olujide, L.O., Akinola, S.E., Oladeji, S.A., Bakare, B. and Aaron, O.I. (2021) Prospective Evaluation of Outcomes of Mechanical Devices in Women with Symptomatic Pelvic Organ Prolapse in Ogbomoso, South-Western Nigeria. Open Journal of Obstetrics and Gynecology, 11, 461-473. https://doi.org/10.4236/ojog.2021.114044

Received: March 24, 2021

Accepted: April 24, 2021

Published: April 27, 2021

Copyright ( 2021 by author(s) and Scientific Research Publishing Inc. This work is licensed under the Creative Commons Attribution International License (CC BY 4.0).

http://creativecommons.org/licenses/by/4.0/

\section{(c) (i) Open Access}

\begin{abstract}
Background: Symptomatic pelvic organ prolapse (POP) impacts the sufferers' quality of life negatively. There is a preference for a mechanical device in certain conditions though the definitive management of POP is surgical. Objectives: We conducted the study to evaluate the outcome of management of POP using mechanical devices. Methods: It was a prospective study. It took place in the gynecology unit of the Bowen University Teaching Hospital Ogbomoso between May 2014 and April 2019. We followed up with eligible patients who opted for pessary use for a median duration of 18 months (Range 12 - 84 months). We excluded those who refuse to participate in the study. Results: Of the 127 patients with symptomatic POP, seventy-five (59.1\%) opted for the use of mechanical devices, and 70 successfully retained them four weeks after insertion. We lost Six (9.2\%) patients to follow up. Of the 64 women included in the analysis, 16 (25\%) discontinued use at some point after four weeks, whereas $36(56.3 \%)$ used the pessary successfully throughout the follow-up period. Overall, $12.1 \%$ of the women experienced minor complications (6.9\% pain or discomfort, 3.2\% excoriation or bleeding, and $2.0 \%$ dis-impaction or constipation). After cessation of pessary use, 12 (25\%) of the 48 women chose surgery, and 10 (20.8\%) chose no further treatment. Conclusion: This study concluded that pessary use for pelvic organ prolapse is safe in low resource settings. Therefore, it is justifiable to offer pessaries in the
\end{abstract}


initial management of uterovaginal prolapse to all patients who opt for conservative management and those awaiting surgery.

\section{Keywords}

Mechanical Device, Symptomatic Pelvic Organ Prolapse, Complications, Discontinuation

\section{Introduction}

Pessaries have been in existence in one form or another since biblical times [1], and currently, many different kinds of pessaries are available to treat the various types of pelvic descent. We defined Pelvic organ prolapse (POP or U-V prolapse) as any pelvic structure that protrudes into the vagina (cystocele, rectocele, enterocele) [2]. Patients with asymptomatic prolapse who are asymptomatic do not require treatment

Though surgery is the definitive treatment for symptomatic U-V prolapse in this era of safe anesthesia, there is a preference for medical management in situations where a woman is still desirous of more children with $3^{\text {rd }}$-degree $U-V$ prolapse. Patients who are not fit for surgery, those who refuse surgery and women with $\mathrm{U}-\mathrm{V}$ prolapse in pregnancy can also use pessary. Those with $\mathrm{U}-\mathrm{V}$ prolapse in pregnancy can also use a pessary. We also use a pessary to relieve acute urinary retention or pain due to incarcerated retroverted uterus in pregnancy, treatment of unsuccessful surgical repair, and neonatal pelvic organ prolapse [3]. Furthermore, the pessary helps relieve symptoms while the patient is awaiting surgery. Physicians also use it as a diagnostic tool amongst patients with stress incontinence. Pessary insertion in this condition is to confirm that surgery will be helpful to the patient [3]. Other forms of treatment modalities for U-V prolapse include general measures in the forms of estrogen use by menopausal women, physiotherapy, and electrical stimulation. These forms of treatment, however, are only used for mild conditions of U-V prolapse [3]. Pessary fitting is an art rather than a science, a trial and error process whereby the clinician's training and experience best predict success [4]. The subjective nature of pessary fitting comes from little or no formal clinical training. Furthermore, there is no consensus on clinical indications for various types of pessaries, patient characteristics for sizing, or appropriate pessary care [4] [5]. Manufacturer product information and texts give general guidelines for pessary fitting; however, the previous survey did not support this recommendation [6]. Unfortunately, the modern vaginal pessary is not readily available in the Nigerian market. This scarcity is probably due to the low prescription rate by doctors and its high cost. The result is that medical practitioners denied many patients who should benefit from vaginal pessary therapy this benefit [3]. There is a lack of data on pessary's use as a viable alternative to surgery in women with POP in Nigeria, hence the need for this study. 
This present study evaluated the use of vaginal pessaries for pelvic organ prolapse ( $\mathrm{POP}$ ) and identified complications and reasons for discontinuing pessary use over the follow-up period prospectively. This present study will serve as baseline data for references and further research.

\section{Materials and Methods}

\subsection{Study Setting}

This study is a prospective study of patients with symptomatic POP who opted for mechanical device (vaginal pessary) insertion as a management option at the Department of Obstetrics' gynecological unit Gynaecology, Bowen University Teaching Hospital, Ogbomoso between May 2014 and April 2019.

\subsection{Ethical Consideration}

We obtained ethical clearance to carry out this study from the ethics and research committee of the Bowen University Teaching Hospital, Ogbomoso, Oyo state. During data collection, we informed patients about the study, confidentiality, and the right not to participate or withdraw at any time without affecting their health or other services. We presented written and verbal information about Pessary insertion to the patients and obtained informed consent. We gave a printed educational leaflet on the procedure to literate patients.

\subsection{Inclusion/Exclusion Criteria}

We excluded those who refused to participate in the study. We selected patients after clinical, laboratory, and radiological evaluation to eliminate significant co-morbidities.

\subsection{Patients' Procedure of Mechanical Device Insertion and Follow-Up}

After the initial evaluation, eligible patients will undergo the counseling section on insertion, removal, and vaginal pessary maintenance. Postmenopausal women require three months of topical estrogen applied 2 or 3 times weekly before fitting a pessary comfortably.

Materials needed include a set of fitting rings, gloves, lubricant, and an autoclave. The moment a patient has decided to try a pessary, she will return on a separate visit for fitting. The visit includes fitting the pessary, having the patient try it temporarily, rechecking the fitting. We fit pessaries by trial and error.

We placed the patient in the lithotomy position and examined it at rest. The researchers observed as she bears down slowly with the Valsalva maneuver (not by coughing, as this is too brief). We then insert a lubricated speculum and rotate it $90^{\circ}$. We then gently open it so that the anterior and posterior walls are visible, both at rest and with the Valsalva maneuver. One can see prolapse in the opposite compartment. We describe three degrees of uterovaginal prolapse using the location of the lowest part of the prolapsed uterus in relation to the level of 
the hymen [7]. The researchers then assess the prolapse while the patient is straining. We diagnose the First-degree prolapse when the descent is still within the vagina, second-degree when it has descended to the introitus, and third-degree when it has fallen outside the introitus [7]. If the prolapse is $1^{\text {st }}$ or $2^{\text {nd }}$ degree, a ring pessary is an excellent treatment, though we offered those with $3^{\text {rd }}$ degree who opted for pessary the mechanical device with considerable success.

\subsection{Fitting a Pessary}

We begin by inserting the middle finger behind the cervix in the posterior fornix and the index finger against the pubic notch. We then use the distance between these two fingers as a starting point in pessary sizing. The researcher will withdraw the fingers and choose the fitting ring whose diameter best approximates this distance. We then fold the fitting ring in half, lightly lubricate the entering end, and insert it so that part of the ring is behind the cervix and the opposite side is behind the pubic notch. We are aiming for the largest size that fits comfortably. The index finger is swept around the perimeter of the ring to check for pressure points. If the ring does not fit properly, we try a smaller or larger size. The average pessary size is 4 or 5 , the range being from 2 to $7 \mathrm{~cm}$. The patient then spends about an hour walking around and tries to void.

When she returns, we will remove the fitting ring and insert the appropriate pessary. We treat a cystocele using a ring with support (filled-in center) while using a ring without support (hollow) for U-V prolapse. We treat stress incontinence using a ring with a knob. We use Gelhorn Pessary in advanced POP (Figure 1 \& Figure 2). We consider a fitting as proper and adequate when the provider could place a finger between the pessary and the vaginal walls, and after fitting, the subject could stand cough and strain with the pessary retained. Multiple pessaries could be fitted at one visit to determine the correct size for subject use. We consider a pessary fitting unsuccessful if the interventionist failed to obtain a good fit after three attempts. Also, it is unsuccessful if the participant found the pessary painful or the participant did not plan to use the pessary after fitting.

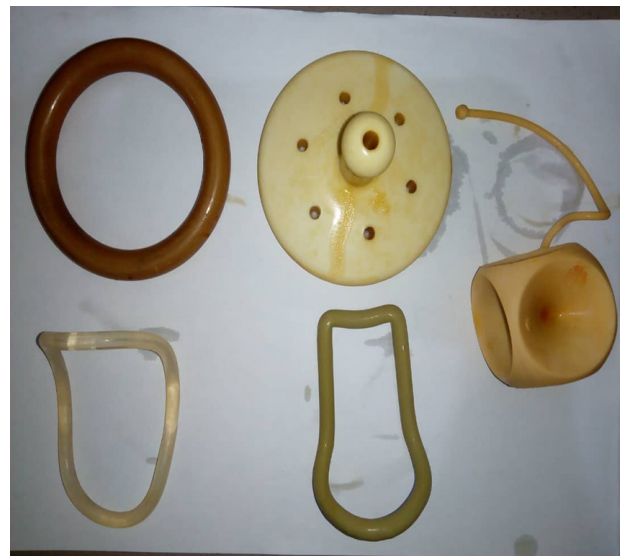

Figure 1. Different vaginal pessaries in our clinic (From the left to right: Portex ring pessary, Shelf pessary, Doughnut pessary, and Gelhorn pessaries). 


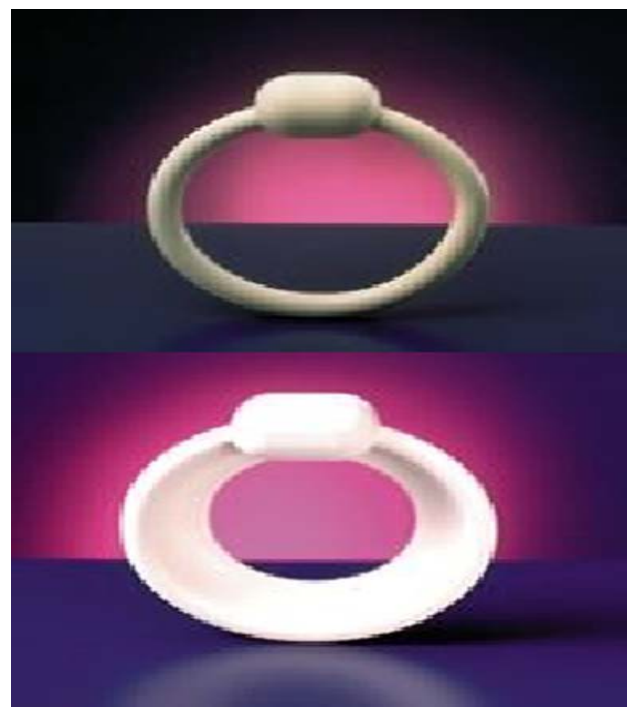

Figure 2. Incontinence ring and incontinence dish (courtesy of Milex website).

\subsection{Follow Up}

The interventionist must check the patient within a week after the new pessary insertion. He then sees the patient at the clinic in 4 weeks. He will note all those who successfully retain their pessaries for four weeks. We examine all patients wearing pessaries every 3 to 6 months to check for vaginal erosions or ulcers. We removed the pessaries in those with lesions until the lesions have healed and treated affected areas with topical estrogen.

Pessaries can be removed every day, every week, or monthly, at patients' discretion. They remove the pessaries for washing with soap and water. Patients can leave ring pessaries in place or removed for intercourse. Patients can also insert their pessaries as needed (e.g., to address stress incontinence with exercise). We removed, washed, and re-inserted their pessaries every 3 to 6 months for those who could not care for the devices on their own. An acidifier or estrogen was applied vaginally 2 or 3 times weekly to reduce infections and odors. We can also use Oral or transdermal estrogen or an estradiol-17 ring (placed behind the pessary) in some patients.

\subsection{Data Collection}

We recruited every consecutive eligible patient at presentation to the facility. We used standardized proforma to collect information on the socio-demographic characteristics of the patients. These include the patients' age, parity, and occupation. We obtained the clinical presentation, predisposing factors, and POP etiologies from the patients' history. We also recorded the weight (in Kilogram) and the patients' height (in Meters). The researchers also classify the POP, the indications for pessary uses, and the type of vaginal pessary inserted. We recorded all this information in the proforma and updated these records at every clinic visit. 


\subsection{Data Analysis}

We carried out data entry and analysis using Statistical Package for Social Sciences (SPSS) version 20. The researchers represented the Socio-demographic characteristics, POP's clinical presentation, and other outcome variables in frequency distribution and simple percentages. We presented appropriate variables in flowcharts and line graphs.

\section{Results}

The prevalence of POP calculated from this study was 5.4\% (54 per 1000) of total gynecological conditions managed during the study. Of the 127 patients with symptomatic POP, seventy-five (59.1\%) opted to use various mechanical devices (as shown in Figure 1 and Figure 2). Seventy (93.3\%) patients successfully retained them four weeks after insertion. We lost six (9.2\%) patients to follow up, as shown in the flowchart in Figure 3. The mean age at presentation in this study was $51.4 \pm 3.3$ years. The mean parity of the patients was $4.2 \pm 1.6$. Grand multiparity accounted for $77.4 \%$ of the cases. Approximately $90.3 \%$ were at least 40years old, while the remaining $9.7 \%$ were younger than 40 . The majority of the patient $(66.7 \%)$ had $2^{\text {nd }}$-degree prolapse. A sensation of something protruding through the vagina was the most frequent presentation (80\%), followed by low back pain $(58.7 \%)$, while 14 patients (18.7\%) had decubitus ulcers at presentation. Difficult deliveries at home or with TBAs accounted for $62.7 \%$, while menopause and chronic cough predisposed $53.3 \%$ and $20.0 \%$ to prolapse in this study, as shown in Table 1.

The most frequent indication for pessary use was patients' refusal of surgical treatment (40\%), while fertility preservation was the reason in $21.3 \%$. Eleven (14.7\%) patients had pessary due to simultaneous stress urinary incontinence (SI), as shown in Table 2. Of the 127 women with prolapse, 75 (59.1\%) had pessary fitted. Seventy (93.3\%) out of the 75 patients that had pessary fitted returned still using it at four weeks. Because of concomitant stress incontinence, 11 women chose ring pessary with a knob for bladder neck support and two after failed portex ring fitting (see blue-shaded areas in Figure 3). Fifty-two patients chose surgical management from the onset while five patients later opted for surgery after a failed pessary fitting making a total of 57 (57/127, 44.9\%) patients.

Thirty-six out of the 64 patients (56.3\%) continued to use pessary at the study end-point. Twelve (18.8\%) died with pessary in situ, while 16 (25\%) discontinued pessary use. Of those who stopped, the median duration of use was 1.1 years (range 0.5 - 4 years). As shown in Figure 4, about $50 \%$ of the patients had discontinued pessary use by 1.6 years. Reasons for discontinuation were diverse. The majority was due to complications from pessary use (50\%). Some stopped when they were ready for surgery (25\%), while others discontinued due to convenience (25\%). The most typical complication of pessary use among the study participants is copious vaginal discharge (35.9\%), while $1.6 \%$ developed deeply impacted pessary that we removed in the theatre under anesthesia, as shown in Table 3. 
A. O. Fehintola et al.

Table 1. Descriptive statistics of patients who had mechanical device insertion for POP.

\begin{tabular}{|c|c|c|}
\hline Variables & Frequency $(\mathrm{n}=75)$ & Percentage (\%) \\
\hline \multicolumn{3}{|l|}{ Age (in years) } \\
\hline$<40$ & 07 & 9.3 \\
\hline$\geq 40$ & 68 & 90.7 \\
\hline Mean $( \pm$ SD) & $51.4( \pm 3.3)$ & \\
\hline \multicolumn{3}{|l|}{ Parity } \\
\hline 0 & 04 & 5.3 \\
\hline $1-4$ & 13 & 17.3 \\
\hline$\geq 5$ & 58 & 77.4 \\
\hline Mean $( \pm$ SD) & $4.2( \pm 1.6)$ & \\
\hline \multicolumn{3}{|l|}{ Classification of POP } \\
\hline $1^{\text {st }}$ degree & 03 & 4.0 \\
\hline $2^{\text {nd }}$ degree & 50 & 66.7 \\
\hline $3^{\text {rd }}$ degree & 22 & 29.3 \\
\hline \multicolumn{3}{|l|}{ Clinical presentation of POP } \\
\hline $\begin{array}{l}\text { Sensation of something } \\
\text { coming down the vagina }\end{array}$ & 60 & 80.0 \\
\hline Dysuria & 18 & 24.0 \\
\hline Decubitus ulcers & 14 & 18.7 \\
\hline Stress incontinence & 11 & 14.7 \\
\hline Urinary retention & 02 & 2.7 \\
\hline Low backache & 44 & 58.7 \\
\hline Others & 16 & 21.3 \\
\hline \multicolumn{3}{|l|}{ Etiologies of POP } \\
\hline Difficult labo ${ }^{\mathrm{rs}}$ & 47 & 62.7 \\
\hline Postmenopausal & 40 & 53.3 \\
\hline Chronic cough & 15 & 20.0 \\
\hline Lifting heavy objects & 30 & 40.0 \\
\hline Others $^{\mathrm{x}}$ & 10 & 13.3 \\
\hline \multicolumn{3}{|l|}{ BMI $\left(\mathrm{kg} / \mathrm{m}^{2}\right)$} \\
\hline$<25.0$ & 44 & 58.7 \\
\hline $25-29.9$ & 20 & 26.7 \\
\hline$\geq 30.0$ & 11 & 14.6 \\
\hline Mean $( \pm$ SD) & $23.4( \pm 3.6)$ & \\
\hline \multicolumn{3}{|l|}{ Types of pessary } \\
\hline Ring pessary & 64 & 85.3 \\
\hline Ring pessary with a knob & 11 & 14.7 \\
\hline
\end{tabular}




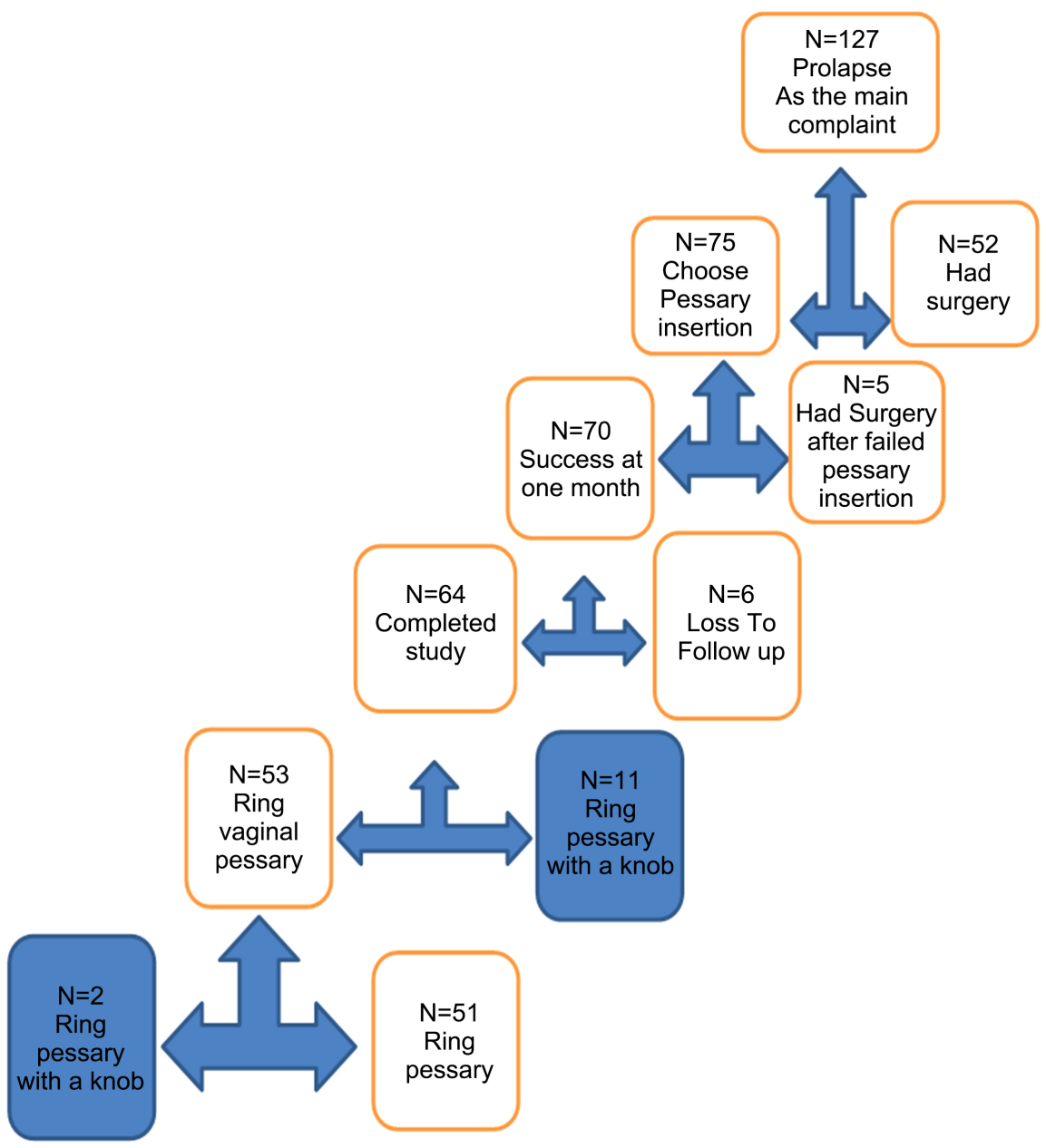

Figure 3. Flow chart of women with prolapse as the primary complaint.

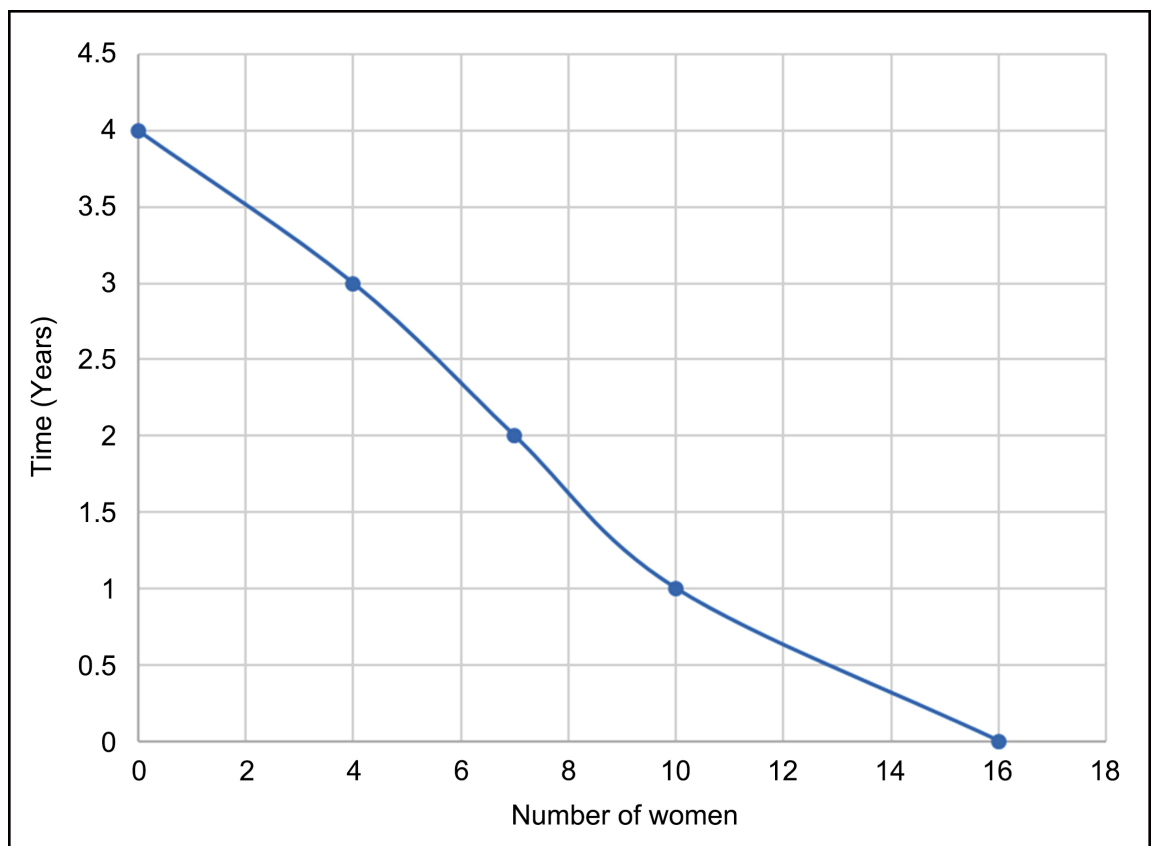

Figure 4. Graph of the duration of pessary use in those who discontinued pessary use. 
Table 2. Indications and outcome of pessary insertion.

\begin{tabular}{ccc}
\hline Variable & Frequency $(\mathrm{n}=75)$ & Percentage $(\%)$ \\
\hline Indications for pessary use & 30 & 40.0 \\
Surgery refusal & 16 & 21.3 \\
Fertility preservation & 05 & 6.7 \\
Poor surgical risk & 07 & 9.3 \\
UVP in pregnancy & 06 & 8.0 \\
Awaiting surgery & 11 & 14.7 \\
Diagnostic test (SI) & & \\
Outcome of insertion & 70 & 93.3 \\
Successful & 05 & 6.7 \\
Unsuccessful & & \\
\hline
\end{tabular}

Table 3. Complications of vaginal pessaries.

\begin{tabular}{ccc}
\hline Variables & Frequency $(\mathrm{n}=64)$ & Percentage $(\%)$ \\
\hline Vaginal bleeding & 19 & 29.7 \\
Copious vaginal discharge & 23 & 35.9 \\
Pain/constipation & 17 & 26.6 \\
Theatre for removal & 01 & 1.6 \\
Urinary incontinence & 02 & 3.2 \\
\hline
\end{tabular}

${ }^{\mathrm{x}}$ multiple responses.

\section{Discussion}

$\mathrm{POP}$ is a highly prevalent condition that is becoming more common as the population ages. It is of considerable importance to the practicing gynecologist in the tropics because of its strong association with repeated childbirth and poor labor conduct. It is one of the most frequent indications for surgery and attendance at the gynecology clinic. However, epidemiologic studies of its prevalence are rare [8] [9].

In a study of 1006 women between ages 18 and 83 presenting for routine gynecological care, only $24 \%$ had normal support, $38 \%$ had $1^{\text {st }}$ degree, $35 \%$ had $2^{\text {nd }}$ degree, and $2 \%$ had $3^{\text {rd }}$ degree POP. Therefore, some loss of pelvic organ support is present in most adult women [10].

Currently available treatments for symptomatic POP include physiotherapy, mechanical devices, and reconstructive surgery. However, surgery has a known reoperation rate of $10 \%-30 \%$ [11] [12].

Gynecologists have different opinions about offering pessaries to women. A study from the American Urogynecology Society in the year 2000 reported that $77 \%$ of the doctors provided pessaries as first-line therapy for pelvic organ prolapse, but $12 \%$ only offered pessaries to women who were not surgical candidates 
[13]. The higher the prolapse severity, the more likely they were to choose surgery over expectant management or pessary.

To our knowledge, this present study is the first to report, prospectively, the outcome of pessary uses over a 3- to 6-year period in Nigeria. There is a lack of data on the use of mechanical devices in managing POP in our country. This scarcity may be because modern vaginal pessary is not commonly available in the Nigerian market. This scarcity is probably due to the low prescription rate by doctors and its high cost. The result is that medical practitioners denied many patients who should benefit from vaginal pessary therapy this benefit. Komolafe et al. [3] looked at an affordable alternative to the modern ring pessary in the form of the ring-shaped vulcanized rubber sold as silencer rubber or oil seal rubber in 4 patients with symptomatic POP. They recorded an improvement in symptoms over a short period offollow-up in these patients.

The prevalence of uterovaginal prolapse in this review is 54 per 1000 gynecological patients. This prevalence is similar to the report from Ibadan (45 per 1000 gynecological admissions) but higher than the finding from Lagos, which is 0.74 per 1000 gynecological patients, 7.6 per 1000 gynecological admissions from Ilorin and 21 per 1000 gynecological admissions in Nnewi and Enugu, South-East Nigeria [14] [15].

These prevalence variations might be due to the differences in the populations studied and the differences in the study periods. Previously, people with uterovaginal prolapse rarely presented to the hospital, but nowadays, patients present to the hospital because of increased awareness, hence expanding the prevalence/number of cases. Also, Ogbomoso, being a semi-urban town, has a large proportion of farmers and women who tend to deliver their babies outside hospital settings.

In this study, approximately $59 \%$ of the participants opted for pessary insertion. This finding is similar to the report from previous studies [13] [14] [15]. [16] This high pessary utilization rate may be explained by the fact that there are very few contra-indications to its use, making the physicians, especially in the developed world, offer it to almost every woman with symptomatic POP. The most common indication for pessary uses in this study was the refusal to undergo surgical management. This contrasts with the finding from previous surveys [14] [15] where most women opted for pessary for fertility preservation or poor surgical risk.

The significant aversion to surgical management, as witnessed against most surgical procedures, including Caesarean Section in the developing countries [17], may explain the high prevalence of surgery refusal among the participants in this study. Almost nine out of every ten women who had pessary insertion in this study retained it after four weeks of insertion with significant improvement in their symptoms. This finding is similar to that of Fernando et al., where about $75 \%$ of the women had successful pessary insertion [17]. There is a wide variation in the success rate $(65 \%$ - 97\%) from previous studies [17] [18] [19]. This 
variation occurs because there is no agreement on what is considered successful vaginal pessary fitting. In this study, we consider a vaginal fitting to be successful if the woman carries the pessary for at least four weeks without expulsion and there is improvement in the symptoms.

Although rare with appropriate use, complications with pessaries reported include actinomycosis and bacterial vaginosis [18] [19]. Others are bleeding, discomfort, pain, vaginal erosion, impaction, excoriation, and ulceration, especially with atrophic vaginitis [20]. Researchers reported more severe complications, such as peritonitis, fistula formation [19] [20] erosion into the bladder or bowels and dense adherence to another pelvic structures [21] hydronephrosis, and vaginal cancer [22] in neglected pessaries. Among patients who successfully retained a pessary in our study population, the most typical pessary use complication was mal-odorous vaginal discharge (35.9\%). This finding is comparable to the report of Sarma et al. [23]. This author, in his series, reported copious vaginal discharge in $25.5 \%$ of the patients. Vaginal bleeding was the second leading complication in our study. Vaginal bleeding constituted major stressors for patients, and it is a leading cause of discontinuation of pessary use in our series. Other reasons for discontinuation of vaginal pessary in our study include varying degrees of discomfort and patient readiness for surgical management. This report is similar to those of Hanson et al. [24] and Wu et al. [21] where most of the respondents discontinued their pessaries due to complications and were ready for their surgery.

\section{Limitation of the Study}

The small sample size in this study may impair the generalizability of its findings. However, findings from this study corroborated those of the existing literature in the field of urogynecology.

\section{Conclusion}

This study concluded that pessary use for pelvic organ prolapse is safe in low resource settings and avoids surgery complications. Therefore, it is justifiable to offer pessaries in the initial management of uterovaginal prolapse to all patients who opt for conservative management and those awaiting surgery. This issue is crucial in countries like Nigeria, where there is still a great aversion to surgical management.

\section{Acknowledgements}

We are using this opportunity to acknowledge the valuable contributions of Prof. Adesegun Fatusi of the Department of Community Health, Obafemi Awolowo University Teaching Hospitals Complex, Ile Ife, Osun State. We also appreciate Dr. Olorunfemi Ogundele of the community Medicine department, University of Medical Sciences, Ondo State, Nigeria, for his support in this article's writing. 


\section{Conflicts of Interest}

The authors declare no conflicts of interest regarding the publication of this paper.

\section{References}

[1] Baeßler, K., Aigmüller, T., Albrich, S., Anthuber, C., Finas, D., Fink, T., Fünfgeld, C., Gabriel, B., Henscher, U., Hetzer, F.H. and Hübner, M. (2016) Diagnosis and Therapy of Female Pelvic Organ Prolapse. Guideline of the DGGG, SGGG and OEGGG (S2e-Level, AWMF Registry Number 015/006, April 2016). Geburtshilfe und Frauenheilkunde, 76, 1287-1301. https://doi.org/10.1055/s-0042-119648

[2] Dufour, S., Hondronicols, A. and Flanigan, K. (2019) Enhancing Pelvic Health: Optimizing the Services Provided by Primary Health Care Teams in Ontario by Integrating Physiotherapists. Physiotherapy Canada, 71, 168-175. https://doi.org/10.3138/ptc.2017-81.pc

[3] Komolafe, J.O., Adeyemi, A.S., Odejide, T.O. and Adedokun, K.A. (2007) Adaptation of Vulcanized Rubber as Pessaries for the Treatment of Uterovaginal Prolapse in a Resource-Poor Setting. Tropical Journal of Obstetrics and Gynaecology, 24, 52-55.

[4] Kandadai, P., Mcvay, S., Larrieux, J.R. and O’Dell, K. (2016) Knowledge and Comfort with Pessary Use: A Survey of US Obstetrics and Gynecology Residents. Female Pelvic Medicine \& Reconstructive Surgery, 22, 491-496. https://doi.org/10.1097/SPV.0000000000000322

[5] Cundiff, G.W., Weidner, A.C., Visco, A.G., Bump, R.C. and Addison, W. (2000) A Survey of Pessary Use by Members of the American Urogynecologic Society. Obstetrics \& Gynecology, 95, 931-935. https://doi.org/10.1016/S0029-7844(00)00788-2

[6] Nager, C.W., Richter, H.E., Nygaard, I., Paraiso, M.F., Wu, J.M., Kenton, K., Atnip, S.D. and Spino, C. (2009) Pelvic Floor Disorders Network. Incontinence Pessaries: Size, POPQ Measures, and Successful Fitting. International Urogynecology Journal, 20, 1023-1028. https://doi.org/10.1007/s00192-009-0866-1

[7] Tarney, C.M. and Dorr, C.H. (2003) Relaxation of Pelvic Support. In: DeCherney, A.H. and Nathan, L., Eds., Current Obstetric and Gynecological Diagnosis and Treatment, 9th Edition, McGraw-Hill Companies, New York, 776-797.

[8] Hunsaker, S., Burgio, K., Clark, A., Lapitan, M.C., Nelson, R., Sillen, U., et al. (2005) Epidemiology of Urinary and Fecal Incontinence and Pelvic Organ Prolapse. In: Abrams, P., Cordoza, L., Koury, S. and Wein, A., Eds., 3rd International Consultation on Incontinence, Health Publication, Paris, 255-312.

[9] Barber, M.D. (2016) Pelvic Organ Prolapse. BMJ, 354, i3853

[10] Hooper, G.L. (2018) Person-Centered Care for Patients with Pessaries. Nursing Clinics, 53, 289-301. https://doi.org/10.1016/j.cnur.2018.01.006

[11] Barber, M.D. (2016) Pelvic Organ Prolapse. BMJ, 354, i3853. https://doi.org/10.1136/bmj.i3853

[12] Chung, S.H. and Kim, W.B. (2018) Various Approaches and Treatments for Pelvic Organ Prolapse in Women. Journal of Menopausal Medicine, 24, 155-162. https://doi.org/10.6118/jmm.2018.24.3.155

[13] Price, N., Slack, A., Jwarah, E. and Jackson, S. (2008) The Incidence of Reoperation for Surgically Treated Pelvic Organ Prolapse: An 11-Year Experience. Post Reproductive Health, 14, 145-148. https://doi.org/10.1258/mi.2008.008029

[14] Buakhom, S., Temtanakitpaisan, T., Chongsomchai, C., Sripipattanakul, M. and 
Buppasiri, P. (2020) Can Video Enhance Confidence in Management of Vaginal Pessary: A Randomized Trial. Thai Journal of Obstetrics and Gynaecology.

[15] Ojiyi, E.C., Dike, E.I., Anolue, F.C., Nzewuihe, A.C. and Ejikeme, C.C. (2013) Uterovaginal Prolapse at a University Teaching Hospital in South-East Nigeria. Orient Journal of Medicine, 25, 107-112.

[16] Onowhakpo, E.A., Omo-aghoja, L.O., Akani, C.I. and Feyi-Waboso, P. (2009) Prevalence and Dterminants of Utero-Vaginal Prolapse in Southern Nigeria. Nigerian Journal of Medicine, 50, 29-32. https://www.nigeriamedj.com/text.asp?2009/50/2/29/71936

[17] Awoyinka, B.S., Ayinde, O.A. and Omigbodun, A.O. (2006) Acceptability of Cesarean Delivery to Antenatal Patients in a Tertiary Health Facility in Southwest Nigeria. Journal of Obstetrics and Gynecology, 26, 208-210. https://doi.org/10.1080/01443610500508311

[18] Fernando, R.J., Thakar, R., Sultan, A.H., Shah, S.M. and Jones, P.W. (2006) Effect of Vagina Pessaries on Symptoms Associated with Pelvic Organ Prolapse. Obstetrics \& Gynecology, 108, 93-99. https://doi.org/10.1097/01.AOG.0000222903.38684.cc

[19] Abdulaziz, M.M. (2019) Open Magnet Resonance Imaging: Application of New Technology to Improve the Evaluation of Pelvic Organ Prolapse in Women. Doctoral Dissertation, University of British Columbia, Vancouver, Kelowna.

[20] Alif, B. and Drutz, H.P. (2000) Bacterial Vaginosis Increases in Pessary Users. International Urogynecology Journal, 11, 219-223.

https://doi.org/10.1007/PL00004026

[21] Wu, V., Farrell, S.A., Baskett, T.F. and Flowerdew, G. (1997) A Simplified Protocol for Pessary Management. Obstetrics \& Gynecology, 90, 990-994. https://doi.org/10.1016/S0029-7844(97)00481-X

[22] Bash, K.L. (2000) Review of Vaginal Pessaries. Obstetrical \& Gynecological, 55, 455-460. https://doi.org/10.1097/00006254-200007000-00025

[23] Poma, P.A. (2000) Nonsurgical Management of Genital Prolapse: A Review and Recommendations for Clinical Practice. Journal of Reproductive Medicine, 45, 789-797.

[24] Sarma, S., Ying, T. and Moore, K.H. (2009) Long-Term Vaginal Ring Pessary Use: Discontinuation Rates and Adverse Events. BJOG, 116, 1715-1721. https://doi.org/10.1111/j.1471-0528.2009.02380.x

\section{List of Abbreviations and Acronyms}

$$
\begin{aligned}
& \text { POP = Pelvic Organ Prolapse } \\
& \text { U-V Prolapse = Uterovaginal prolapse } \\
& \text { BMI = Body Mass Index } \\
& \text { SI = Stress Incontinence } \\
& \text { UVP = Uterovaginal prolapse }
\end{aligned}
$$

